\title{
Age-related differences in morbidity and mortality after surgery for primary clinical T4 and locally recurrent rectal cancer
}

\author{
Citation for published version (APA):
}

Ketelaers, S. H. J., Voogt, E. L. K., Simkens, G. A., Bloemen, J. G., Nieuwenhuijzen, G. A. P., de Hingh, I. H. J., Rutten, H. J. T., Burger, J. W. A., \& Orsini, R. G. (2021). Age-related differences in morbidity and mortality after surgery for primary clinical T4 and locally recurrent rectal cancer. Colorectal Disease, 23(5), 1141-1152. https://doi.org/10.1111/codi.15542

Document status and date:

Published: 01/05/2021

DOI:

10.1111/codi.15542

\section{Document Version:}

Publisher's PDF, also known as Version of record

\section{Document license:}

Taverne

Please check the document version of this publication:

- A submitted manuscript is the version of the article upon submission and before peer-review. There can be important differences between the submitted version and the official published version of record. People interested in the research are advised to contact the author for the final version of the publication, or visit the DOI to the publisher's website.

- The final author version and the galley proof are versions of the publication after peer review.

- The final published version features the final layout of the paper including the volume, issue and page numbers.

Link to publication

\footnotetext{
General rights rights.

- You may freely distribute the URL identifying the publication in the public portal. please follow below link for the End User Agreement:

www.umlib.nl/taverne-license

Take down policy

If you believe that this document breaches copyright please contact us at:

repository@maastrichtuniversity.nl

providing details and we will investigate your claim.
}

Copyright and moral rights for the publications made accessible in the public portal are retained by the authors and/or other copyright owners and it is a condition of accessing publications that users recognise and abide by the legal requirements associated with these

- Users may download and print one copy of any publication from the public portal for the purpose of private study or research.

- You may not further distribute the material or use it for any profit-making activity or commercial gain

If the publication is distributed under the terms of Article $25 \mathrm{fa}$ of the Dutch Copyright Act, indicated by the "Taverne" license above, 


\title{
Age-related differences in morbidity and mortality after surgery for primary clinical T4 and locally recurrent rectal cancer
}

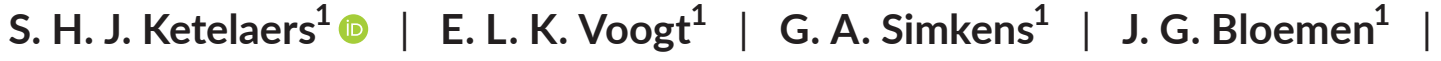 \\ G. A. P. Nieuwenhuijzen ${ }^{1}$ | I. H. J. de Hingh', | H. J. T. Rutten ${ }^{1,2}$ | J. W. A. Burger ${ }^{1}$ | \\ R. G. Orsini ${ }^{3}$
}

${ }^{1}$ Department of Surgery, Catharina Hospital, Eindhoven, The Netherlands

${ }^{2}$ GROW: School of Oncology and Developmental Biology, University of Maastricht, Maastricht, The Netherlands

${ }^{3}$ Department of Surgery, Maastricht University Medical Centre+, Maastricht, The Netherlands

Correspondence

Stijn H.J. Ketelaers, Department of Surgery, Catharina Hospital, PO Box 1350, 5602 ZA, Eindhoven, The Netherlands.

E-mail: stijn.ketelaers@

catharinaziekenhuis.nl

\begin{abstract}
Aim: Outcomes in elderly patients ( $\geq 75$ years) with non-advanced colorectal cancer have improved. It is unclear whether this is also true for elderly patients with clinical T4 rectal cancer (cT4RC) or locally recurrent rectal cancer (LRRC). We aimed to compare agerelated differences in morbidity and mortality after curative treatment for CT4RC and LRRC.

Methods: All cT4RC and LRRC patients without distant metastasis who underwent curative surgery between 2005 and 2017 in the Catharina Hospital (Eindhoven, The Netherlands) were included. Morbidity and mortality were evaluated based on age (<75 and $\geq 75$ years) and date of surgery (2005-2011 and 2012-2017).

Results: Overall, 72 of 474 (15.2\%) cT4RC and 53 of 293 (18.1\%) LRRC patients were $\geq 75$ years. No significant differences in the incidence of Clavien-Dindo I-IV complications were observed between age groups. However, in elderly cT4RC patients, cerebrovascular accidents occurred more frequently $(4.2 \%$ vs. $0.5 \%, P=0.03)$. Between $2005-2011$ and 2012-2017, 30-day mortality improved from $7.5 \%$ to $3.1 \%$ and from $10.0 \%$ to $0.0 \%$ in elderly cT4RC and LRRC patients, respectively. The 1-year mortality during 2012-2017 was worse in elderly than in younger patients ( $28.1 \%$ vs. $6.2 \%, P=0.001$ for cT4RC and $27.3 \%$ vs. $13.8 \%, P=0.06$ for LRRC). In elderly cT4RC and LRRC patients, $44.4 \%$ and $46.2 \%$ died due to non-cancer-related causes, while only $27.8 \%$ and $23.1 \%$ died due to disease recurrence, respectively.

Conclusion: Although the 30-day mortality in elderly cT4RC and LRRC patients improved after curative treatment, the 1-year mortality in elderly patients continued to be high, which requires more awareness for the elderly after hospitalization.

KEYWORDS

rectal cancer, locally advanced, locally recurrent, surgery, elderly, survival
\end{abstract}




\section{INTRODUCTION}

Colorectal cancer (CRC) is one of the most common cancers worldwide with $43 \%$ of patients being older than 75 years [1]. Approximately $10 \%$ of all CRC patients are diagnosed with locally advanced rectal cancer (LARC) and 6\%-10\% will eventually develop locally recurrent rectal cancer (LRRC) [2]. The optimal treatment for patients with LARC and LRRC is neoadjuvant therapy followed by surgery [3]. In LRRC, in particular, involvement of the lateral and posterior pelvic wall is more common since visceral fasciae, which act as natural barriers for tumour infiltration, have already been removed during primary tumour surgery. Therefore, even more extended extra-anatomical resections are often needed in LRRC. These extended resections are associated with postoperative complication rates ranging from $41.5 \%-57 \%[4,5]$.

Almost $30 \%-50 \%$ of surgical procedures are performed in patients $>65$ years old, and with the increase in the elderly population worldwide the incidence may increase further [1,6,7]. In general, elderly patients have multiple comorbidities with varying physical conditions. According to recent literature, most patients $<75$ years are physically healthy, whereas over $50 \%$ of patients $\geq 75$ years have more than two chronic disorders [8,9]. The elderly often experience difficulty coping with complications and longer recovery periods along with increased mortality in the first postoperative year [10-12]. However, improvements in CRC care have led to better outcomes in elderly patients [13-15]. The difference in the postoperative and 1-year mortality rates between younger and elderly CRC patients has decreased with comparable outcomes [11,14,15]. However, it is unclear if this is also true for clinical T4 rectal cancer (cT4RC) or LRRC patients treated with curative intent.

The primary aim of this study was to evaluate the morbidity and mortality of elderly ( $\geq 75$ years) and younger ( $<75$ years) patients with CT4RC and LRRC treated with curative intent. Changes in morbidity and mortality were also analysed over time in order to evaluate whether improvements in care could have contributed to better outcomes in elderly patients.

\section{METHODS}

\section{Patients and treatment}

Patients who underwent curative surgery for primary CT4RC or LRRC at the Catharina Hospital (Eindhoven, The Netherlands), a tertiary referral centre for such patients, between 2005 and 2017 were included. Patients with peritoneal or incurable distant metastases were excluded. All patients with cT4RC had a histological diagnosis and radiological confirmation of visceral peritoneum or surrounding organ involvement. Diagnosis of LRRC was based on histology or imaging. Positron emission tomography CT was performed to exclude distant metastases and distinguish between fibrosis or LRRC when a biopsy could not be obtained and CT of chest and abdomen was performed to detect distant metastases. All patients underwent pelvic MRI for accurate staging before and after neoadjuvant treatment. Most patients
What does this paper add to the literature?

In contrast to the more recently described improved survival rates after curative treatment in elderly nonadvanced colorectal cancer patients, those with advanced or recurrent rectal cancer still have worse 1-year mortality rates compared to younger patients. More awareness for the period after hospitalization could be beneficial.

with cT4RC underwent neoadjuvant treatment according to the Dutch National Guidelines for rectal cancer [16]. The majority underwent long course chemoradiation with up to $50.4 \mathrm{~Gy}$ in 28 fractions with concomitant oral capecitabine. LRRC patients who were previously irradiated underwent reirradiation with $30 \mathrm{~Gy}$ with concomitant oral capecitabine [17]. LRRC patients without a history of pelvic irradiation received a full course of irradiation (50.4 Gy) with concomitant oral capecitabine [17]. Some patients with extensive disease also received neoadjuvant induction chemotherapy followed by (re)irradiation with or without concomitant chemotherapy to achieve downstaging. Details of this treatment regimen and the influence on outcomes have been reported previously [18]. After 8-12 weeks, surgery was performed combined with intraoperative radiotherapy at a dose of 10-12.5 Gy at the margins considered at risk (perioperatively or positive margins confirmed by intraoperative frozen section analysis).

\section{Clinical data and follow-up}

Patients' characteristics, data on treatment, pathology and additional clinical (e.g., complications, hospital readmission) and demographic data were retrospectively extracted from the medical records. Complications were scored using the Clavien-Dindo classification [19]. Follow-up data were obtained from the medical records, the referral hospital or the patient's general practitioner. Follow-up was calculated as the interval between surgery and last contact or death. The minimum follow-up of all patients was 1 year (if alive). During follow-up, local recurrence and distant metastases were recorded. The Municipal Administrative Databases were consulted to obtain information on survival data. If a patient died during follow-up, the specific cause of death was investigated. Treatment-induced deterioration, as a cause of mortality, was defined as deterioration of the physiological status after hospital discharge leading to death, regardless of postoperative complications and without signs of relapsing disease, cardiopulmonary disease or cerebrovascular accidents.

\section{Statistical analyses}

Statistical analyses were performed using SPSS Statistics 25.0 software (IBM), separately for CT4RC and LRRC. The study period was 
divided into two time periods of 7 and 6 years, respectively (20052011 and 2012-2017). The primary endpoint was postoperative mortality (30-day, 90-day and 1-year). Secondary endpoints were postoperative complications (Clavien-Dindo classification) and causes of 1-year mortality. Comparisons were stratified by age (<75 and $\geq 75$ years) and date of surgery (2005-2011 and 2012-2017). Intergroup comparisons were analysed using the chi-squared test or Fisher's exact test, when appropriate, for non-continuous data. Independent $t$ tests or Mann-Whitney $U$ tests were used for normally and non-normally distributed continuous data, respectively. A $P$ value of $<0.05$ was considered statistically significant. All tests were two-sided. Survival rates for both patient groups were estimated separately and stratified by age group using the Kaplan-Meier method and compared using the log-rank test. Relative survival rates were calculated as the absolute survival amongst cT4RC and LRRC patients divided by the expected survival for the general population with the same sex and age. In-depth analyses were performed to identify the specific cause of death.

\section{RESULTS}

A total of 767 patients were included. Of the 474 cT4RC and 293 LRRC patients, 72 (15.2\%) and 53 (18.1\%), respectively, were $\geq 75$ years. The median follow-ups were 3.8 and 2.8 years for cT4RC and LRRC patients, respectively. In the LRRC group, one patient was lost to follow-up in the first postoperative year. Clinical and demographic characteristics for CT4RC and LRRC patients are presented in Tables 1 and 2, respectively. In both groups, elderly patients had significantly higher comorbidities.

\section{Postoperative morbidity}

No significant differences were observed in the incidence of ClavienDindo Grade I-IV complications based on age in either the CT4RC or LRRC groups, but patients $<75$ years were more likely to have an uncomplicated postoperative course than patients $\geq 75$ years $(P=0.02$ for CT4RC and $P=0.001$ for LRRC). More pulmonary complications were observed among cT4RC and LRRC patients $\geq 75$ years than among patients $<75$ years $(22.2 \%$ vs. $8.7 \%, P=0.001$ for cT4RC, and $26.4 \%$ vs. $14.2 \%, P=0.03$ for LRRC). Older CT4RC patients experienced more postoperative delirium and cerebrovascular accidents than younger patients $(11.1 \%$ vs. $1.0 \%, P<0.001$ for delirium, and $4.2 \%$ vs. $0.5 \%$, $P=0.03$ for cerebrovascular accidents). More delirium was also observed in LRRC patients $\geq 75$ years than in patients $<75$ years $(17.0 \%$ vs. $2.5 \%, P<0.001)$. Other than fascial dehiscence in LRRC patients (9.4\% vs. $1.7 \%, P=0.01$ ), surgical complications and reintervention rates (endoscopic, radiological and surgical) were not significantly different between elderly and younger cT4RC and LRRC patients $(16.7 \%$ vs. $18.4 \%, P=0.72$, and $41.5 \%$ vs. $28.7 \%, P=0.07$, respectively). $A$ more detailed description of complications in both groups is presented in Table 3.

\section{Mortality}

The 30-day mortality decreased over time for both cT4RC and LRRC patients $\geq 75$ years, from $7.5 \%$ and $10.0 \%$, respectively, for the period 2005-2011, to $3.1 \%$ and $0.0 \%$, respectively, for the period 2012 2017. Comparable 30-day mortality rates were observed for cT4RC and LRRC patients $<75$ years in both time periods $(0.5 \%$ vs. $1.5 \%$ for CT4RC, respectively, and $2.9 \%$ vs. $1.4 \%$ for LRRC, respectively). The 30-day mortality rates were significantly different between CT4RC patients $<75$ and $\geq 75$ years in the period 2005-2011 but were comparable for the latter period ( $P=0.01$ and $P=0.46$, respectively). Among LRRC patients, no significant differences in 30-day mortality were observed based on age in either time period. The 90-day mortality rates did not improve over time. For cT4RC patients, the 90-day mortality rates in the period 2012-2017 were $9.4 \%$ and $2.1 \%$ for patients $\geq 75$ years and those $<75$ years, respectively. The corresponding rates for patients with LRRC were $9.1 \%$ and $2.2 \%$, respectively.

The 1-year mortality rate for CT4RC patients $\geq 75$ years was significantly worse than for patients $<75$ years and did not improve over time $(22.5 \%$ vs. $5.8 \%, P=0.002$ for $2005-2011$, and $28.1 \%$ vs. $6.2 \%, P=0.001$ for $2012-2017$ ). Among LRRC patients $<75$ years, the 1-year mortality improved non-significantly over time $(20.6 \%$ vs. $13.8 \%, P=0.16$ ) and no improvements over time were observed among elderly patients. The differences in 1-year mortality between the two age groups for LRRC were not significant $(P>0.99$ for 20052011 and $P=0.06$ for 2012-2017). For both cT4RC and LRRC patients, assessing relative survival did not change these results. A more detailed description of mortality rates during the first year and overall and cancer-specific survival for the entire study period is presented in Tables 4 and 5, respectively. In Figure 1-4 Kaplan-Meier curves on absolute 1-year survival for the different time periods are presented. The causes of death in the first postoperative year are summarized in Table 6.

\section{DISCUSSION}

In this study, we compared the morbidity and mortality of elderly and younger CT4RC and LRRC patients and analysed differences over time. In elderly cT4RC and LRRC patients, the 30-day mortality rates improved over the years to $3.1 \%$ and $0.0 \%$, respectively, which were comparable with younger patients. Unfortunately, the 90-day and 1-year mortality rates were still significantly worse for elderly patients. Approximately $25 \%$ of elderly cT4RC or LRRC patients died in the first postoperative year, compared to $6.0 \%$ and $16.7 \%$ of younger patients, respectively, over the entire study period. Of the elderly patients who died in the first postoperative year, most died due to treatment-induced or non-cancer-related causes. Disease recurrence, however, was the main cause of death in patients $<75$ years.

More non-surgical complications were observed in elderly patients; however, no significant differences in the incidence of 


\begin{tabular}{|c|c|c|c|}
\hline & $<75$ years & $\geq 75$ years & \\
\hline & $n=402$ & $n=72$ & \\
\hline & $n(\%)$ & $n(\%)$ & $P$ value \\
\hline $\begin{array}{l}\text { Mean age in years at time of surgery } \\
( \pm \text { SD })\end{array}$ & $61.4(8.6)$ & $79.2(3.6)$ & $<0.001$ \\
\hline Median follow-up in years (IQR) & $4.0(2.7-5.5)$ & $2.5(1.1-4.9)$ & $<0.001$ \\
\hline Male & $235(58.5)$ & $39(54.2)$ & 0.50 \\
\hline \multicolumn{4}{|l|}{ Comorbidity } \\
\hline None & $148(36.8)$ & $9(12.5)$ & $<0.001$ \\
\hline 1 comorbidity & $121(30.1)$ & $18(25.0)$ & \\
\hline 2 comorbidities & 64 (15.9) & $18(25.0)$ & \\
\hline$\geq 3$ comorbidities & $53(13.2)$ & $23(31.9)$ & \\
\hline Missing & $16(4.0)$ & $4(5.6)$ & \\
\hline \multicolumn{4}{|l|}{ ASA classification } \\
\hline I-II & $328(81.6)$ & $50(69.4)$ & 0.02 \\
\hline III & $60(14.9)$ & $21(29.2)$ & \\
\hline Missing & $14(3.5)$ & $1(1.4)$ & \\
\hline \multicolumn{4}{|l|}{ Neoadjuvant treatment } \\
\hline None & - & $2(2.8)$ & $<0.001$ \\
\hline Short course radiotherapy ( $5 \times 5$ Gy) & $17(4.2)$ & $9(12.5)$ & \\
\hline Long course radiotherapy & $10(2.5)$ & $9(12.5)$ & \\
\hline Chemoradiation & $358(89.1)$ & $46(63.9)$ & \\
\hline Other & $17(4.2)$ & $6(8.3)$ & \\
\hline \multicolumn{4}{|l|}{ Type of surgery } \\
\hline Low anterior resection & $184(45.8)$ & $25(34.7)$ & $<0.001$ \\
\hline $\begin{array}{l}\text { Abdominoperineal/abdominosacral } \\
\text { resection }\end{array}$ & $176(43.8)$ & $34(47.2)$ & \\
\hline Hartmann resection & $8(2.0)$ & $8(11.1)$ & \\
\hline Pelvic exenteration ${ }^{a}$ & $32(8.0)$ & $3(4.2)$ & \\
\hline Other & $2(0.5)$ & $2(2.8)$ & \\
\hline Extended (multivisceral) resection ${ }^{b}$ & $200(49.8)$ & $50(69.4)$ & 0.01 \\
\hline Intraoperative radiotherapy & $278(69.2)$ & $47(65.3)$ & 0.51 \\
\hline Radical resection (R0) & $356(88.6)$ & $56(77.8)$ & 0.01 \\
\hline
\end{tabular}

TABLE 1 Demographic, clinical and tumour characteristics of CT4RC patients $(n=474)$, stratified by age $(<75$ and $\geq 75$ years)

Abbreviations: ASA, American Society of Anesthesiologists; cT4RC, clinical T4 rectal cancer; Gy, Gray; IQR, interquartile range; SD, standard deviation.

${ }^{a}$ Pelvic exenteration was defined as an en bloc resection of the rectum including complete removal of the bladder and reproductive organs (prostate/seminal vesicles, or uterus, ovaries and/or vagina) [2].

${ }^{b}$ Extended (multivisceral) resection is used for other combinations of resections than exenteration.

surgical complications and reinterventions were observed between the two age groups. Clavien-Dindo Grade $\geq$ III complications occurred in $19 \%$ and $31 \%$ of young cT4RC and LRRC patients, and in $24 \%$ and $45 \%$ of elderly CT4RC and LRRC patients, respectively, which is comparable to other studies in which $25 \%$ of cT4RC and $36 \%$ of LRRC patients experienced Grade $\geq$ III complications $[20,21]$. Although the morbidity of elderly patients remains high, the 30-day mortality has improved over time, which is observed for all stages of colon and rectal cancer and probably reflects improved perioperative and postoperative care [14,15,22-25]. The literature also showed improvements in 1-year mortality and comparable survival for elderly and younger patients with Stage I-III CRC, but in this study of CT4RC and LRRC patients no improvements in 90-day and 1-year overall mortalities were observed $[14,15]$. We found no significant influence of postoperative complications on mortality among elderly patients and, as many patients died after hospitalization due to deterioration, a delayed effect of treatment on the physical condition of these patients could be hypothesized. Among patients with LRRC, higher mortality rates were also observed among the elderly, but the differences were 
TABLE 2 Demographic, clinical and tumour characteristics of LRRC patients $(n=293)$, stratified by age ( $<75$ and $\geq 75$ years)

\begin{tabular}{|c|c|c|c|}
\hline & $<75$ years & $\geq 75$ years & \\
\hline & $n=240$ & $n=53$ & \\
\hline & $n(\%)$ & $n(\%)$ & $P$ value \\
\hline $\begin{array}{l}\text { Mean age in years at time of surgery } \\
( \pm S D)\end{array}$ & $62.7(8.2)$ & $78.6(3.2)$ & $<0.001$ \\
\hline Median follow-up in years (IQR) & $2.8(1.4-4.1)$ & $2.3(0.9-3.9)$ & 0.09 \\
\hline Male & $161(67.1)$ & $36(67.9)$ & 0.91 \\
\hline \multicolumn{4}{|l|}{ Comorbidity } \\
\hline None & $90(37.5)$ & $9(17.0)$ & \multirow[t]{4}{*}{0.01} \\
\hline 1 comorbidity & $70(29.2)$ & $14(26.4)$ & \\
\hline 2 comorbidities & $44(18.3)$ & $16(30.2)$ & \\
\hline$\geq 3$ comorbidities & $36(15.0)$ & $14(26.4)$ & \\
\hline \multicolumn{4}{|l|}{ ASA classification } \\
\hline I-II & $204(85.0)$ & $41(77.4)$ & \multirow[t]{3}{*}{0.36} \\
\hline III & $28(11.7)$ & $10(18.9)$ & \\
\hline Missing & $8(3.3)$ & $2(3.8)$ & \\
\hline \multicolumn{4}{|l|}{ Neoadjuvant treatment } \\
\hline None & $16(6.7)$ & $5(9.4)$ & \multirow[t]{5}{*}{0.09} \\
\hline Re-irradiation only & $7(2.9)$ & 1 (1.9) & \\
\hline $\begin{array}{l}\text { Re-irradiation with concomitant } \\
\text { chemotherapy }\end{array}$ & $143(59.6)$ & $23(43.4)$ & \\
\hline $\begin{array}{l}\text { Full course irradiation with } \\
\text { concomitant chemotherapy }\end{array}$ & $69(28.8)$ & $20(37.7)$ & \\
\hline Full course irradiation only & $5(2.1)$ & $4(7.5)$ & \\
\hline \multicolumn{4}{|l|}{ Type of surgery } \\
\hline Low anterior resection & $37(15.4)$ & $6(11.3)$ & \multirow[t]{6}{*}{0.01} \\
\hline $\begin{array}{l}\text { Abdominoperineal/abdominosacral } \\
\text { resection }\end{array}$ & $91(37.9)$ & $22(41.5)$ & \\
\hline Hartmann resection & $10(4.2)$ & $4(7.5)$ & \\
\hline Pelvic exenteration ${ }^{a}$ & $38(15.8)$ & $7(13.2)$ & \\
\hline Debulking & $60(25.0)$ & $8(15.1)$ & \\
\hline Other & $4(1.7)$ & $6(11.3)$ & \\
\hline Extended (multivisceral) resection ${ }^{\mathrm{b}}$ & $131(54.6)$ & $28(52.8)$ & 0.82 \\
\hline Intraoperative radiotherapy & $208(86.7)$ & $38(71.7)$ & 0.01 \\
\hline Radical resection (RO) & $139(57.9)$ & $38(71.7)$ & 0.06 \\
\hline
\end{tabular}

Abbreviations: ASA, American Society of Anesthesiologists; IQR, interquartile range; LRRC, locally recurrent rectal cancer. Also see comment in Table 1 about abbreviations SD and Gy.

${ }^{\text {aPelvic }}$ exenteration was defined as an en bloc resection of the rectum including complete removal of the bladder and reproductive organs (prostate/seminal vesicles, or uterus, ovaries and/or vagina) [2].

${ }^{b}$ Extended (multivisceral) resection is used for other combinations of resections than exenteration. smaller compared with patients $<75$ years than those observed among CT4RC patients. It is likely that poor oncological behaviour of these recurrent tumours has a relatively large influence on survival for both age groups.

The mortality rates presented in this study are based on relatively small patient groups, but are supported by population-based studies on outcomes in LARC in Northern European countries and the USA, where reported 30 - and 90-day mortality rates range from
4.0\%-14.5\%, depending on stage $[13,26]$. Another Dutch study with LARC and LRRC patients treated with total pelvic exenteration found 90-day mortality rates similar to ours [2]. Our 1-year mortality rates are also in accordance with other studies which range from $21 \%-26.5 \%$ for locally advanced cases $[2,13]$.

In our institution, surgery for cT4RC and LRRC is performed open with extended or multivisceral resections, whereas minimally invasive surgery is the standard of care for non-advanced cases. 


\begin{tabular}{|c|c|c|c|c|}
\hline & \multicolumn{2}{|l|}{ cT4RC } & \multicolumn{2}{|l|}{ LRRC } \\
\hline & $<75$ years & $\geq 75$ years & $<75$ years & $\geq 75$ years \\
\hline & $n=402$ & $n=72$ & $n=240$ & $n=53$ \\
\hline & $n(\%)$ & $n(\%)$ & $n(\%)$ & $n(\%)$ \\
\hline $\begin{array}{l}\text { Median admission time in } \\
\text { days (IQR) }\end{array}$ & $\begin{array}{l}9.0 \\
(7.0-14.0)\end{array}$ & $9.0(7.0-16.0)$ & $\begin{array}{l}12.0 \\
(7.0-17.0)\end{array}$ & $\begin{array}{l}12.0 \\
(8.0-20.5)\end{array}$ \\
\hline $\begin{array}{l}\text { Median admission on ICU } \\
\text { in days (IQR) }\end{array}$ & $\begin{array}{l}1.0 \\
(0.0-1.0)^{\mathrm{a}}\end{array}$ & $1.0(1.0-2.0)^{\mathrm{a}}$ & $1.0(1.0-2.0)$ & $1.0(1.0-2.5)$ \\
\hline Surgical complications ${ }^{b}$ & $136(33.8)$ & $26(36.1)$ & $130(54.2)$ & $35(66.0)$ \\
\hline Anastomotic leakage & $19(4.7)$ & $4(5.6)$ & $10(4.2)$ & $3(5.7)$ \\
\hline Clavien-Dindo $\geq I I I$ & $3(0.7)$ & $2(2.8)$ & $7(2.9)$ & $2(3.8)$ \\
\hline Presacral abscess & $46(11.4)$ & $5(6.9)$ & $48(20.0)$ & $12(22.6)$ \\
\hline Clavien-Dindo $\geq \mathrm{III}$ & $28(7.0)$ & $2(2.8)$ & $36(15.0)$ & $9(17.0)$ \\
\hline Intra-abdominal abscess & $15(3.7)$ & $1(1.4)$ & $23(9.6)$ & $6(11.3)$ \\
\hline Clavien-Dindo $\geq I I I$ & $9(2.2)$ & - & $14(5.8)$ & $6(11.3)$ \\
\hline Ileus & $49(12.2)$ & $14(19.4)$ & $62(25.8)$ & $13(24.5)$ \\
\hline Clavien-Dindo $\geq I I I$ & $1(0.2)$ & $2(2.8)$ & $2(0.8)$ & - \\
\hline Fascial dehiscence & $8(2.0)$ & $2(2.8)$ & $4(1.7)^{a}$ & $5(9.4)^{a}$ \\
\hline Wound infection & $44(10.9)$ & $9(12.5)$ & $57(23.8)$ & $15(28.3)$ \\
\hline Abdominal & $24(6.0)$ & $4(5.6)$ & $27(11.3)$ & $4(7.5)$ \\
\hline Perineal & $20(5.0)$ & $5(6.9)$ & $30(12.5)$ & $11(20.8)$ \\
\hline $\begin{array}{l}\text { Non-surgical } \\
\text { complications }^{b}\end{array}$ & $136(33.8)^{\mathrm{a}}$ & $39(54.2)^{\mathrm{a}}$ & $111(46.3)^{\mathrm{a}}$ & $34(64.2)^{\mathrm{a}}$ \\
\hline Urological & $95(23.6)$ & $20(27.8)$ & 79 (32.9) & $24(45.3)$ \\
\hline Pulmonary & $35(8.7)^{\mathrm{a}}$ & $16(22.2)^{\mathrm{a}}$ & $34(14.2)^{a}$ & $14(26.4)^{\mathrm{a}}$ \\
\hline Cardiac & $25(6.2)$ & $9(12.5)$ & $15(6.3)$ & $5(9.4)$ \\
\hline $\begin{array}{l}\text { Venous } \\
\text { thromboembolism }\end{array}$ & $11(2.7)$ & - & $5(2.1)$ & $1(1.9)$ \\
\hline \multicolumn{5}{|l|}{ Neurological } \\
\hline $\begin{array}{l}\text { Cerebrovascular } \\
\text { accident }\end{array}$ & $2(0.5)^{a}$ & $3(4.2)^{\mathrm{a}}$ & $1(0.4)$ & $1(1.9)$ \\
\hline Delirium & $4(1.0)^{a}$ & $8(11.1)^{a}$ & $6(2.5)^{\mathrm{a}}$ & $9(17.0)^{\mathrm{a}}$ \\
\hline \multicolumn{5}{|c|}{ Complication grade according to Clavien-Dindo } \\
\hline None & $154(38.3)^{\mathrm{a}}$ & $17(23.6)^{\mathrm{a}}$ & $55(22.9)^{\mathrm{a}}$ & $2(3.8)^{a}$ \\
\hline Grade I-II & $167(41.5)$ & $38(52.8)$ & $108(45.0)$ & $25(47.2)$ \\
\hline Grade IIIa + IIIb & $57(14.2)$ & 8 (11.1) & $60(25.0)$ & $16(30.2)$ \\
\hline Grade IV & $14(3.5)$ & $4(5.6)$ & $10(4.2)$ & $4(7.5)$ \\
\hline Grade V & $6(1.5)^{\mathrm{a}}$ & $5(6.9)^{\mathrm{a}}$ & $4(1.7)^{a}$ & $4(7.5)^{a}$ \\
\hline Missing & $4(1.0)$ & - & $3(1.3)$ & $2(3.8)$ \\
\hline
\end{tabular}

TABLE 3 Details on postoperative outcomes of CT4RC and LRRC patients, stratified by age ( $<75$ and $\geq 75$ years)

Abbreviations: cT4RC, clinical T4 rectal cancer; ICU, intensive care unit; IQR, interquartile range; LRRC, locally recurrent rectal cancer.

${ }^{\mathrm{a} P}<0.05$.

${ }^{b}$ Number of patients who had at least one surgical or one non-surgical complication, respectively.

Extended tumour involvement in the pelvic wall was more often observed in LRRC than CT4RC, requiring more extensive extraanatomical exenterations such as unilateral or bilateral pelvic side wall or sacral resections (Table S1). It has been hypothesized that when stressors reach a certain threshold and homeostatic mechanisms are no longer able to compensate, functional decline with impaired health status and further diminishment of physiological reserve capacity may occur, leading to decreased resilience to future stressors [27]. The impact of major rectal surgery and hospitalization could therefore induce increased vulnerability with a higher risk of death in the first postoperative year when other stressors appear. Although this effect is more often seen in frail people, this 


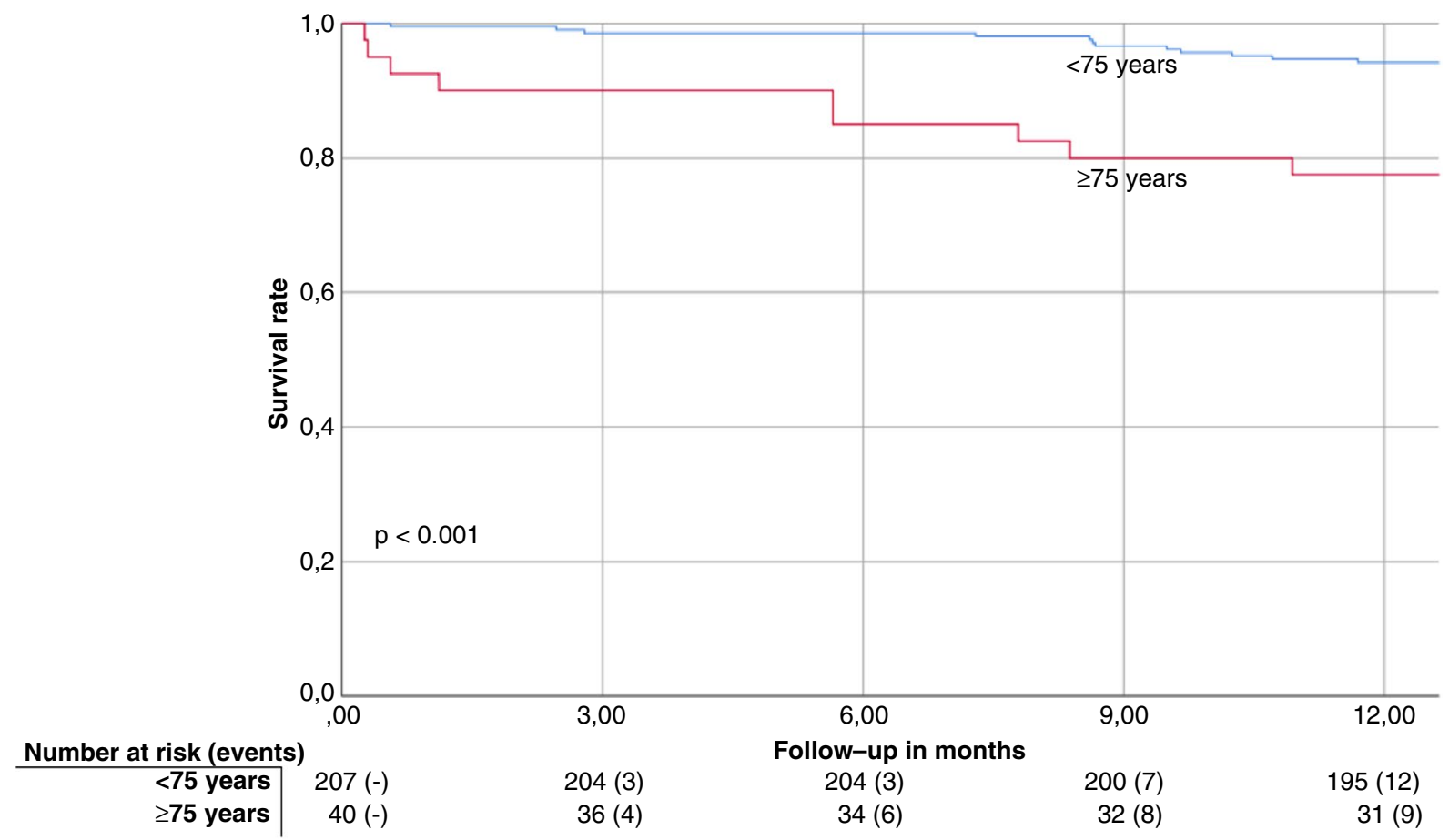

FIGURE 1 Kaplan-Meier curve for absolute 1-year survival for cT4RC patients for the period 2005-2011 ( $n=247)$, stratified by age (<75 and $\geq 75$ years)

phenomenon could explain the higher mortality rates seen in this study in contrast to other studies of Stage I-III CRC patients [14,15].

Patients' physiological status was evaluated preoperatively by a surgeon and an anaesthesiologist, and multidisciplinary team meeting decisions were based on tumour and patient characteristics and preferences. If the surgeon or anaesthesiologist suspected a poor physiological status, the patient was referred to a geriatrician for a more comprehensive geriatric screening and to improve performance status. Identifying frailty in elderly patients is important as it is a predictor of postoperative complications and shorter life

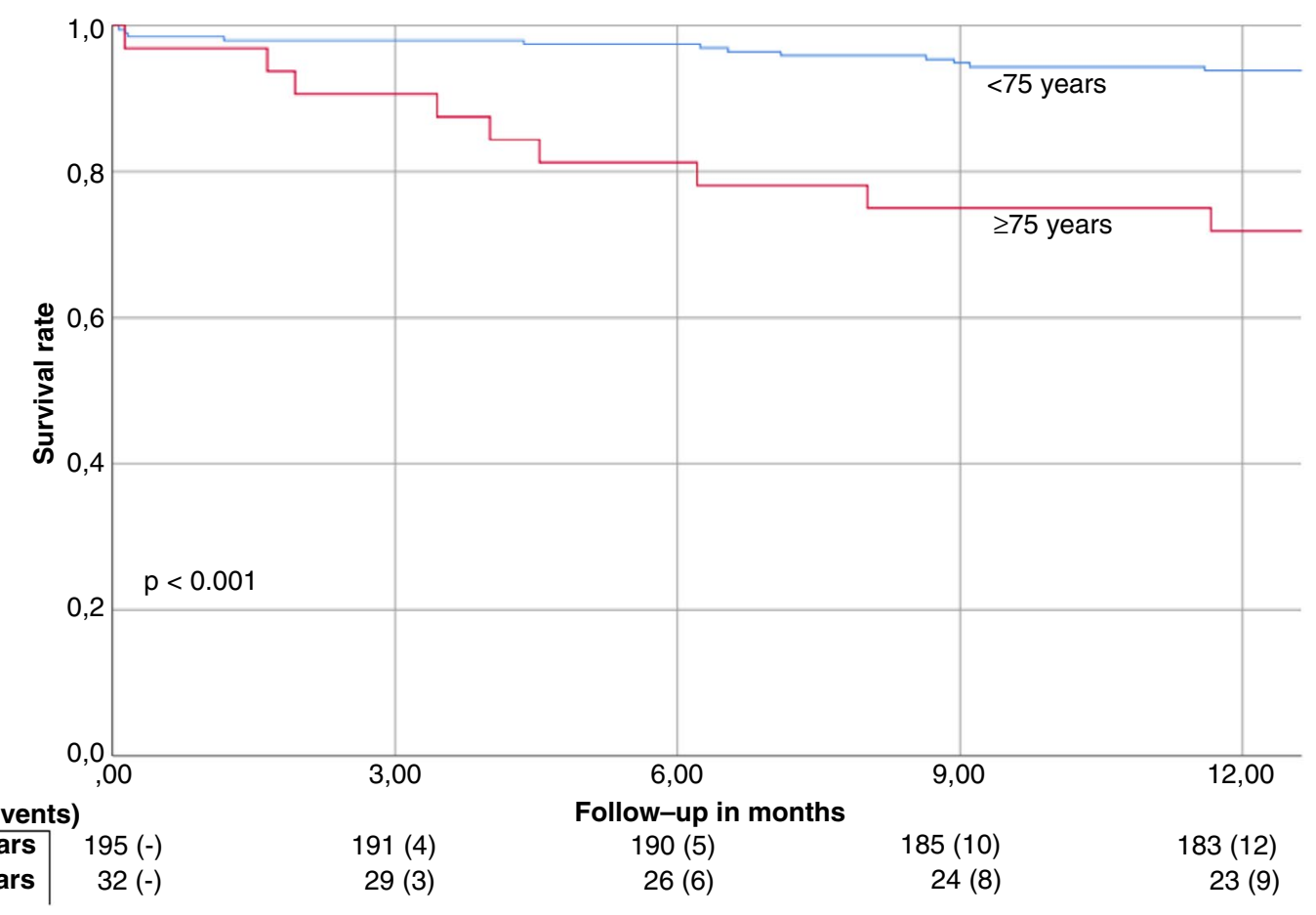

FIGURE 2 Kaplan-Meier curve for absolute 1-year survival for cT4RC patients for the period 2012-2017 ( $n=227)$, stratified by age (<75 and $\geq 75$ years) 


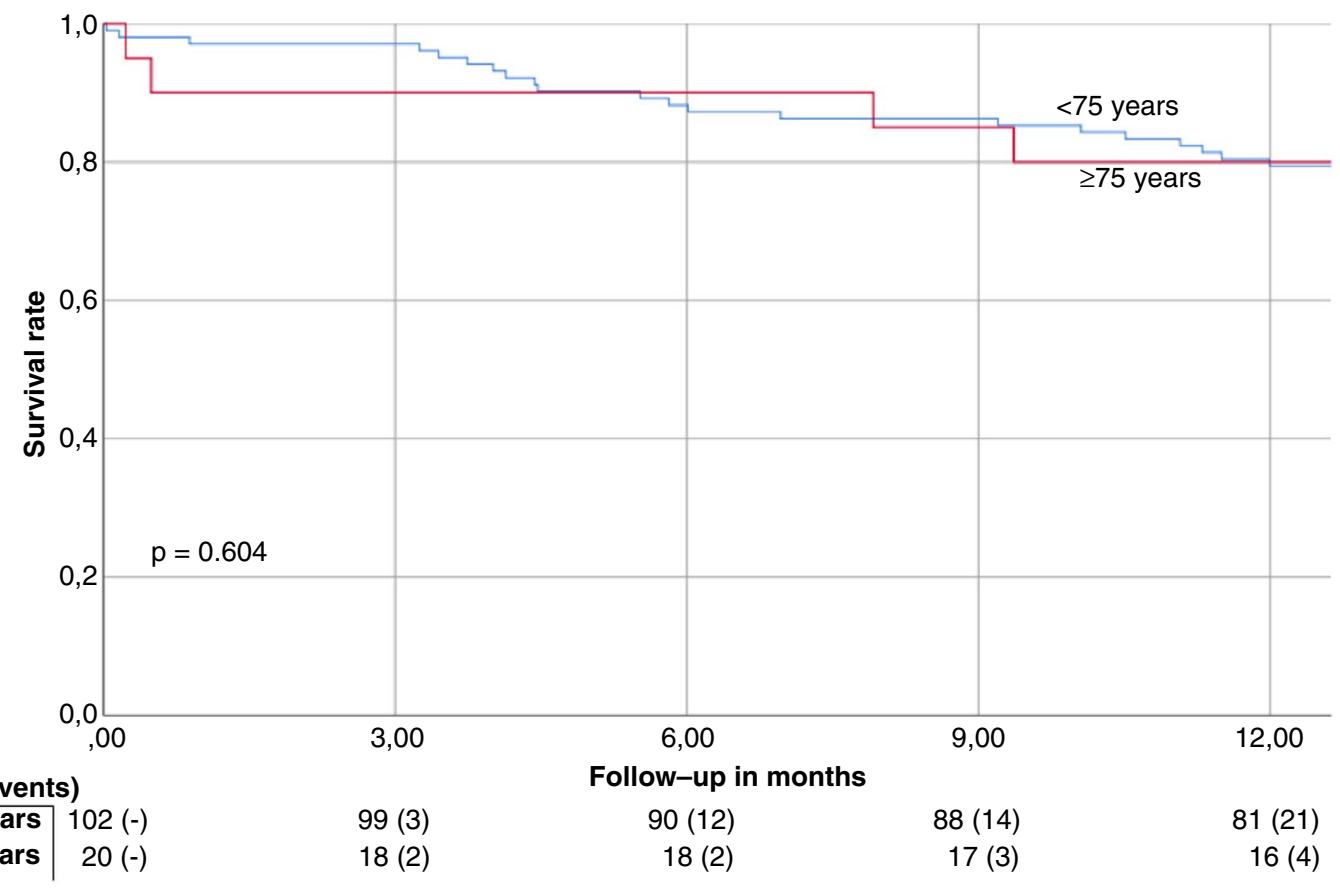

FIG URE 3 Kaplan-Meier curve for absolute 1-year survival for LRRC patients for the period 2005-2011 ( $n=122)$, stratified by age (<75 and $\geq 75$ years)

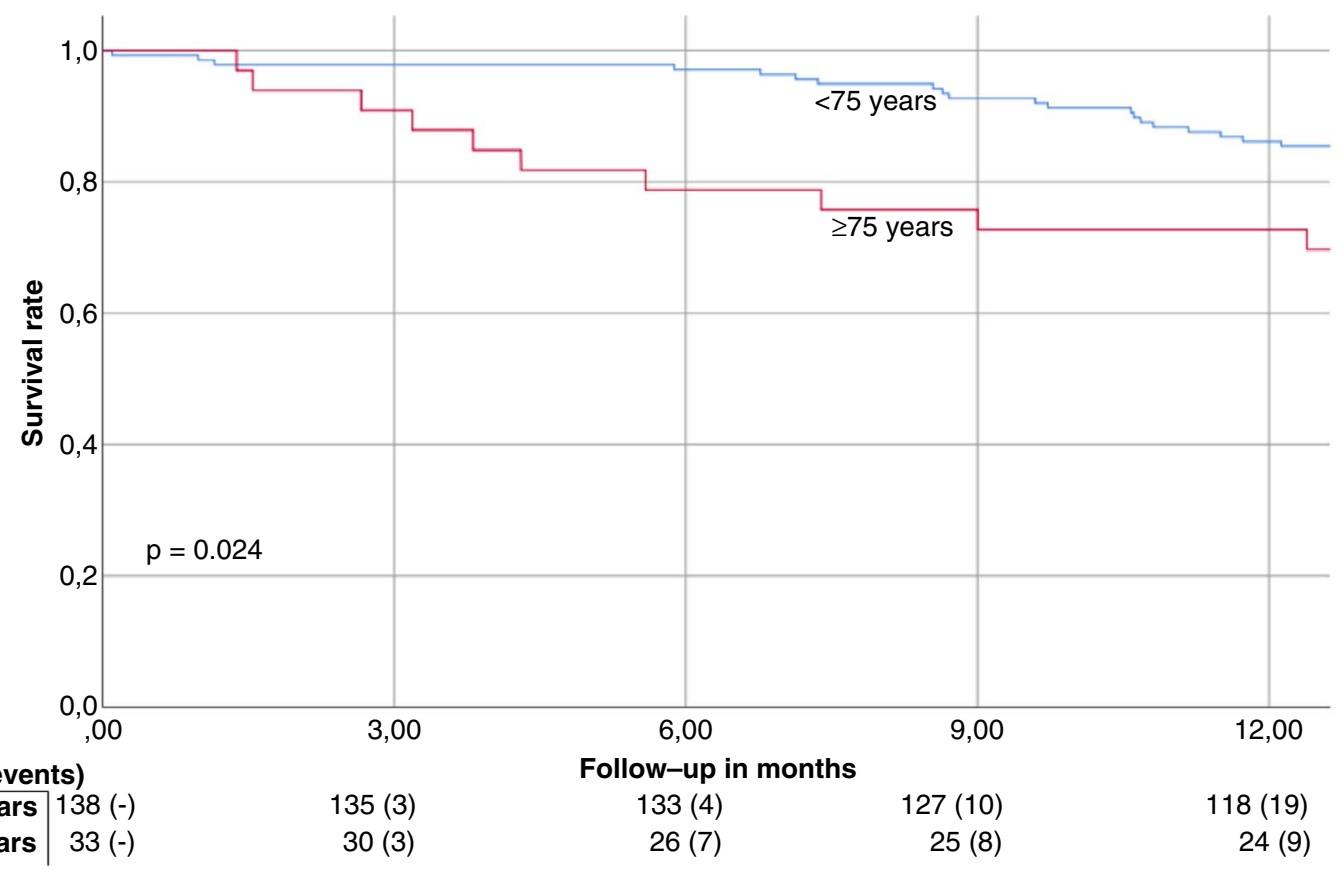

FIGURE 4 Kaplan-Meier curve for absolute 1-year survival for LRRC patients for the period 2012-2017 ( $n=171)$, stratified by age ( $<75$ and $\geq 75$ years)

expectancy [28,29]. Although all elderly patients in this study were preoperatively considered fit for multimodality treatment and surgery, the 1-year mortality rates remained high, which shows how extremely difficult it is to distinguish elderly patients at risk for increased mortality in the first postoperative year from those who are not. As not all of our patients underwent a geriatric assessment, estimating frailty and 1-year mortality risk should be considered for every elderly patient with cT4RC or LRRC.

Another possible intervention to improve outcomes could be prehabilitation. Supervised prehabilitation programmes have shown promise in improving physical condition and outcomes in patients unfit for surgery, but the role of these programmes in this specific 
TAB LE 4 Absolute mortality rates of both cT4RC and LRRC patients after surgery, stratified by age ( $<75$ and $\geq 75$ years) and period of surgery (2005-2011 and 2012-2017)

\begin{tabular}{|c|c|c|c|c|c|c|}
\hline & \multicolumn{3}{|l|}{ cT4RC } & \multicolumn{3}{|l|}{ LRRC } \\
\hline 30-day & $0.5 \%$ & $7.5 \%$ & 0.01 & $2.9 \%$ & $10.0 \%$ & 0.19 \\
\hline 90-day & $1.4 \%$ & $10.0 \%$ & 0.01 & $2.9 \%$ & $10.0 \%$ & 0.19 \\
\hline 30-day & $1.5 \%$ & $3.1 \%$ & 0.46 & $1.4 \%$ & $0.0 \%$ & $>0.99$ \\
\hline 90-day & $2.1 \%$ & $9.4 \%$ & 0.06 & $2.2 \%$ & $9.1 \%$ & 0.09 \\
\hline 1-year & $6.2 \%$ & $28.1 \%$ & 0.001 & $13.8 \%$ & $27.3 \%$ & 0.06 \\
\hline
\end{tabular}

Abbreviations: cT4RC, clinical T4 rectal cancer; LRRC, locally recurrent rectal cancer.

patient group remains unclear $[30,31]$. In our study, all patients were instructed to increase their protein intake and physical activity in the preoperative period, but a supervised prehabilitation programme was not standard of care during the study period.

The most benefit towards improving mortality rates in elderly patients may be gained in the period after hospitalization. Our results show that a major part of the 1-year mortality in elderly patients occurs in this period, regardless of postoperative complications or disease progression. Elderly patients who are hospitalized after surgery spend a considerable time in bed, leading to rapid muscle loss [32,33]. Sarcopenia has been associated with decreased physical reserve capacity and increased 1-year mortality [34]. Preserving muscle mass in both the early and late

TABLE 5 Overall, cancer-specific and disease-free survival rates for CT4RC and LRRC patients stratified by age ( $<75$ and $\geq 75$ years) for the period 2005-2017

\begin{tabular}{|c|c|c|c|c|}
\hline & $\begin{array}{l}\text { cT4RC } \\
<75 \text { years }\end{array}$ & $\begin{array}{l}\text { cT4RC } \\
\geq 75 \text { years }\end{array}$ & $\begin{array}{l}\text { LRRC } \\
<75 \text { years }\end{array}$ & $\begin{array}{l}\text { LRRC } \\
\geq 75 \text { years }\end{array}$ \\
\hline \multicolumn{5}{|c|}{ Overall survival } \\
\hline 1-year & 0.94 & 0.75 & 0.83 & 0.76 \\
\hline 3-years & 0.79 & 0.54 & 0.56 & 0.45 \\
\hline \multirow[t]{2}{*}{5 -years } & 0.65 & 0.37 & 0.31 & 0.17 \\
\hline & \multicolumn{2}{|c|}{$P<0.001$} & \multicolumn{2}{|c|}{$P=0.06$} \\
\hline \multicolumn{5}{|c|}{ Cancer-specific survival } \\
\hline 1-year & 0.95 & 0.83 & 0.87 & 0.82 \\
\hline 3-years & 0.82 & 0.66 & 0.61 & 0.56 \\
\hline \multirow[t]{2}{*}{5 -years } & 0.73 & 0.56 & 0.35 & 0.32 \\
\hline & \multicolumn{2}{|c|}{$P=0.001$} & \multicolumn{2}{|c|}{$P=0.56$} \\
\hline \multicolumn{5}{|c|}{ Disease-free survival } \\
\hline 1-year & 0.83 & 0.82 & 0.60 & 0.66 \\
\hline 3-years & 0.69 & 0.55 & 0.33 & 0.44 \\
\hline \multirow[t]{2}{*}{ 5-years } & 0.62 & 0.48 & 0.25 & 0.41 \\
\hline & \multicolumn{2}{|c|}{$P=0.10$} & \multicolumn{2}{|c|}{$P=0.08$} \\
\hline
\end{tabular}

Abbreviations: cT4RC, clinical T4 rectal cancer; LRRC, locally recurrent rectal cancer. postoperative phases may increase physical functioning and prevent 1-year mortality in this specific age group. Therefore, rehabilitation programmes should be part of a total prehabilitation, Enhanced Recovery After Surgery and rehabilitation pathway and must be initiated immediately after surgery and continue after discharge [33]. A pilot study showed that elderly patients who received rehabilitation after abdominal emergency surgery had better 'Timed Up and Go' outcomes at 6 weeks after discharge in comparison with those receiving standard care [32]. As high 'Timed Up and Go' scores are a risk factor for both long-term institutionalization and mortality in senior patients, improving this with a rehabilitation programme may result in reduced vulnerability and mortality [35,36]. Additionally, in patients undergoing other types of major gastrointestinal surgery, improvements have been seen in relevant parameters for cardiorespiratory fitness (e.g., $\mathrm{VO}_{2}$ max and the 6-min walking test) after a multidisciplinary rehabilitation programme, although the influence of these programmes on postoperative outcomes and survival remains unclear [37]. In elderly patients with CT4RC or LRRC, survival outcomes may be improved by combining prehabilitation, enhanced recovery and rehabilitation programmes. Studies focusing on this topic in cT4RC or LRRC patients are lacking, and future studies would be of interest.

Other than oncological and survival outcomes, functional outcomes including quality of life can also play a major role in the decision-making process, especially in the elderly population. It is known that the quality of life in elderly CRC patients improves after surgery and is comparable to that in younger patients [38]. Unfortunately, in our study we did not have information about the quality of life. However, earlier studies performed by our research group showed that patients with LRRC had lower health-related quality of life outcomes after surgery compared with patients with non-advanced disease or LARC, regardless of age [39]. More outcomes with respect to the quality of life and functional outcomes of this patient group should be addressed in future prospective studies.

This paper will help educate clinicians and elderly CT4RC and LRRC patients about the possible outcomes and expectations after surgery. In our study, a median length of 9 days of hospital admission 


\begin{tabular}{|c|c|c|c|c|}
\hline & \multirow{2}{*}{$\frac{\text { cT4RC }}{<75 \text { years }}$} & \multirow[b]{2}{*}{$\geq 75$ years } & \multicolumn{2}{|l|}{ LRRC } \\
\hline & & & $<75$ years & $\geq 75$ years \\
\hline & $n=24$ & $n=18$ & $n=40$ & $n=13$ \\
\hline & $n(\%)$ & $n(\%)$ & $n(\%)$ & $n(\%)$ \\
\hline In-hospital mortality ${ }^{a}$ & $6(25.0)$ & $5(27.8)$ & $4(10.0)$ & $4(30.8)$ \\
\hline \multicolumn{5}{|l|}{ Out-of-hospital mortality } \\
\hline Treatment-induced deterioration ${ }^{b}$ & $1(4.2)$ & 2 (11.1) & $6(15.0)$ & $4(30.8)$ \\
\hline Relapsing disease & $11(45.8)$ & $5(27.8)$ & $25(62.5)$ & $3(23.1)$ \\
\hline Cardiopulmonary disease & - & $2(11.1)$ & $2(5.0)$ & $2(15.4)$ \\
\hline Other & - & $1(5.6)$ & - & - \\
\hline Unknown & $6(25.0)$ & $3(16.7)$ & $3(7.5)$ & - \\
\hline
\end{tabular}

TABLE 6 Causes of death of all cT4RC and LRRC patients who died in the first year postoperatively, stratified by age $(<75$ and $\geq 75$ years)

Abbreviations: cT4RC, clinical T4 rectal cancer; LRRC, locally recurrent rectal cancer.

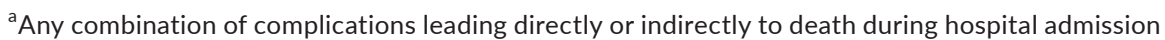
(e.g., renal insufficiency, cardiac failure, respiratory failure etc.). In-depth analyses did not show specific major groups of complications.

${ }^{b}$ Deterioration of the physiological status of the patient after discharge from the hospital, leading to death without signs of relapsing disease, cardiopulmonary disease or cerebrovascular accidents.

for elderly cT4RC patients was observed, with only $24 \%$ having major complications (Clavien-Dindo $\geq \mathrm{III}$ ) and 18\% undergoing reinterventions (endoscopic, radiological and surgical). For elderly LRRC patients, median length of hospital admission was 12 days, $45 \%$ of them had major complications (Clavien-Dindo $\geq 11 \mathrm{I}$ ) and $42 \%$ had to undergo reinterventions (endoscopic, radiological and surgical). Although postoperative mortality is low, clinicians should be aware of the increased vulnerability and mortality in these elderly patients in the first postoperative year.

The strength of this study lies in the availability of many clinically relevant variables in a unique population of cT4RC and LRRC patients with a low prevalence of missing values. Although this is one of the largest single-centre studies with detailed data in this specific population without interhospital variations, the relatively small patient population could have resulted in less statistical power and it could be argued that it lacks generalizability to other centres. An important limitation of this study is that we were only able to study those patients who underwent surgery, with no information on patients who died preoperatively or were not eligible for or declined surgery. Furthermore, as we are a referral centre for these advanced and recurrent cases, the referral of patients could have resulted in some selection bias. The retrospective nature of this study is another limitation, with underestimation of minor complications due to lack of documentation. However, by accurately and thoroughly studying the medical records and contact with referral hospitals and general practitioners, an underestimation of complications was kept to a minimum.

\section{CONCLUSION}

Advances in rectal cancer care have led to equal short-term postoperative outcomes in elderly and younger patients, but 90-day and 1-year mortality rates did not improve over time. Approximately one out of four elderly CT4RC and LRRC patients died in the first postoperative year and, as the majority died after hospitalization without disease recurrence, more awareness is needed towards patient care in the period after hospitalization.

\section{PATIENT CONSENT STATEMENT}

No formal patient consent was required in this study, as this was a retrospective archive study with no physical involvement of the subjects. The data were already available and were not collected specifically for a medical-scientific research purpose.

\section{PERMISSION TO REPRODUCE MATERIAL FROM OTHER SOURCES}

Not applicable.

\section{CLINICAL TRIAL REGISTRATION}

Not applicable.

\section{CONFLICT OF INTEREST}

The authors declare that they have no conflicts of interest.

\section{ETHICAL APPROVAL}

No ethics approval was required for this study, as this was a retrospective archive study with no physical involvement of the subjects. There was no infringement of the physical or psychological integrity of the subjects. The data were already available and were not collected specifically for a medical-scientific research purpose. 
Therefore, the study was not subject to the Medical Research Involving Human Subjects Act.

\section{DATA AVAILABILITY STATEMENT}

The data that support the findings of this study are available from the corresponding author upon reasonable request.

\section{ORCID}

S. H. J. Ketelaers (D) https://orcid.org/0000-0002-0756-5894

\section{REFERENCES}

1. Millan M, Merino S, Caro A, Feliu F, Escuder J, Francesch T. Treatment of colorectal cancer in the elderly. World J Gastrointest Oncol. 2015;7:204-20.

2. Hagemans JAW, Rothbarth J, Kirkels WJ, Boormans JL, van Meerten E, Nuyttens JJME, et al. Total pelvic exenteration for locally advanced and locally recurrent rectal cancer in the elderly. Eur J Surg Oncol. 2018;44:1548-54.

3. Courtney D, McDermott F, Heeney A, Winter DC. Clinical review: surgical management of locally advanced and recurrent colorectal cancer. Langenbecks Arch Surg. 2014;399:33-40.

4. Mohan HM, Evans MD, Larkin JO, Beynon J, Winter DC. Multivisceral resection in colorectal cancer: a systematic review. Ann Surg Oncol. 2013;20:2929-36.

5. Yang TX, Morris DL, Chua TC. Pelvic exenteration for rectal cancer: a systematic review. Dis Colon Rectum. 2013;56:519-31.

6. Yang R, Wolfson M, Lewis MC. Unique aspects of the elderly surgical population: an anesthesiologist's perspective. Geriatr Orthop Surg Rehabil. 2011;2:56-64.

7. Deiner S, Westlake B, Dutton RP. Patterns of surgical care and complications in elderly adults. J Am Geriatr Soc. 2014;62:829-35.

8. Ouchi $\mathrm{Y}$, Rakugi $\mathrm{H}$, Arai $\mathrm{H}$, Akishita $\mathrm{M}$, Ito $\mathrm{H}$, Toba $\mathrm{K}$, et al. Redefining the elderly as aged 75 years and older: proposal from the Joint Committee of Japan Gerontological Society and the Japan Geriatrics Society. Geriatr Gerontol Int. 2017;17:1045-7.

9. Barnett K, Mercer SW, Norbury M, Watt G, Wyke S, Guthrie B. Epidemiology of multimorbidity and implications for health care, research, and medical education: a cross-sectional study. Lancet. 2012;380:37-43.

10. Dekker JWT, van den Broek CBM, Bastiaannet E, van de Geest LGM, Tollenaar RAEM, Liefers GJ. Importance of the first postoperative year in the prognosis of elderly colorectal cancer patients. Ann Surg Oncol. 2011;18:1533-9.

11. Rutten HJ, den Dulk M, Lemmens VE, van de Velde CJ, Marijnen CA. Controversies of total mesorectal excision for rectal cancer in elderly patients. Lancet Oncol. 2008;9:494-501.

12. Schiphorst A, Verweij NM, Pronk A, Hamaker ME. Age-related guideline adherence and outcome in low rectal cancer. Dis Colon Rectum. 2014;57:967-75.

13. Claassen YHM, Bastiaannet E, van Eycken E, Van Damme N, Martling A, Johansson R, et al. Time trends of short-term mortality for octogenarians undergoing a colorectal resection in North Europe. Eur J Surg Oncol. 2019;45:1396-402.

14. Brouwer NPM, Heil TC, Olde Rikkert MGM, Lemmens VEPP, Rutten HJT, de Wilt JHW, et al. The gap in postoperative outcome between older and younger patients with stage I-III colorectal cancer has been bridged; results from the Netherlands Cancer Registry. Eur J Cancer. 2019;116:1-9.

15. Ketelaers SHJ, Orsini RG, Burger JWA, Nieuwenhuijzen GAP, Rutten HJT. Significant improvement in postoperative and 1-year mortality after colorectal cancer surgery in recent years. Eur J Surg Oncol. 2019;45:2052-8.
16. Federation of Medical Specialists. Duch National Guidelines Colorectal Cancer. 2014. https://richtlijnendatabase.nl/richtlijn/ colorectaal_carcinoom_crc/startpagina_-_crc.html

17. Bosman SJ, Holman FA, Nieuwenhuijzen GAP, Martijn H, Creemers GJ, Rutten HJ. Feasibility of reirradiation in the treatment of locally recurrent rectal cancer. Br J Surg. 2014;101:1280-9.

18. Voogt ELK, van Zoggel DMGI, Kusters M, Nieuwenhuijzen GAP, Bloemen JG, Peulen HMU, et al. Improved outcomes for responders after treatment with induction chemotherapy and chemo(re) irradiation for locally recurrent rectal cancer. Ann Surg Oncol. 2020;27:3503-13. https://doi.org/10.1245/s10434-020-08362-4

19. Clavien PA, Barkun J, de Oliveira ML, Vauthey JN, Dindo D, Schulick RiD, et al. The Clavien-Dindo classification of surgical complications: five-year experience. Ann Surg. 2009;250:187-96.

20. Berkel AEM, Woutersen DP, van der Palen J, Klaase JM. Prognostic factors for postoperative morbidity and tumour response after neoadjuvant chemoradiation followed by resection for rectal cancer. J Gastrointest Surg. 2014;18:1648-57.

21. Alberda WJ, Verhoef C, Nuyttens JJ, Rothbarth J, van Meerten E, de Wilt JHW, et al. Outcome in patients with resectable locally recurrent rectal cancer after total mesorectal excision with and without previous neoadjuvant radiotherapy for the primary rectal tumor. Ann Surg Oncol. 2014;21:520-6.

22. van Rooijen SJ, Huisman D, Stuijvenberg M, Stens J, Roumen RMH, Daams F, et al. Intraoperative modifiable risk factors of colorectal anastomotic leakage: why surgeons and anesthesiologists should act together. Int J Surg. 2016;36:183-200.

23. Miller TE, Roche AM, Mythen M. Fluid management and goaldirected therapy as an adjunct to Enhanced Recovery After Surgery (ERAS). Can J Anesth. 2015;62:158-68.

24. Bainbridge D, Martin J, Arango M, Cheng D. Perioperative and anaesthetic-related mortality in developed and developing countries: a systematic review and meta-analysis. Lancet. 2012;380:1075-81.

25. Tejedor P, Pastor C, Gonzalez-Ayora S, Ortega-Lopez M, Guadalajara H, Garcia-Olmo D. Short-term outcomes and benefits of ERAS program in elderly patients undergoing colorectal surgery: a case-matched study compared to conventional care. Int J Colorectal Dis. 2018;33:1251-8.

26. Sineshaw HM, Yabroff KR, Tsikitis VL, Jemal A, Mitin T. Early mortality after resection of locally advanced rectal cancer in elderly United States patients. J Clin Oncol. 2019;37:11529.

27. Lang PO, Michel JP, Zekry D. Frailty syndrome: a transitional state in a dynamic process. Gerontology. 2009;55:539-49.

28. Fagard K, Leonard S, Deschodt M, Devriendt E, Wolthuis A, Prenen $\mathrm{H}$, et al. The impact of frailty on postoperative outcomes in individuals aged 65 and over undergoing elective surgery for colorectal cancer: a systematic review. J Geriatr Oncol. 2016;7:479-91.

29. Lin HS, Watts JN, Peel NM, Hubbard RE. Frailty and post-operative outcomes in older surgical patients: a systematic review. BMC Geriatr. 2016;16:157.

30. Barberan-Garcia A, Ubré M, Roca J, Lacy AM, Burgos F, Risco R, et al. Personalised prehabilitation in high-risk patients undergoing elective major abdominal surgery: a randomized blinded controlled trial. Ann Surg. 2018;267:50-6.

31. Hughes MJ, Hackney RJ, Lamb PJ, Wigmore SJ, Christopher Deans DA, Skipworth RJE. Prehabilitation before major abdominal surgery: a systematic review and meta-analysis. World J Surg. 2019;43:1661-8.

32. McComb A, Warkentin LM, McNeely ML, Khadaroo RG. Development of a reconditioning program for elderly abdominal surgery patients: the Elder-friendly Approaches to the Surgical Environment-BEdside reconditioning for Functional ImprovemenTs (EASE-BE FIT) pilot study. World J Emerg Surg. 2018;13:21.

33. Hoogeboom TJ, Dronkers JJ, Hulzebos EHJ, van Meeteren NLU. Merits of exercise therapy before and after major surgery. Curr Opin Anaesthesiol. 2014;27:161-6. 
34. Otten L, Stobäus N, Franz K, Genton L, Müller-Werdan U, Wirth $\mathrm{R}$, et al. Impact of sarcopenia on 1-year mortality in older patients with cancer. Age Ageing. 2019;48:413-8.

35. Bergland A, Jørgensen L, Emaus N, Strand BH. Mobility as a predictor of all-cause mortality in older men and women: 11.8 year follow-up in the Tromsø study. BMC Health Serv Res. 2017;17:22.

36. Huisman M, Ghignone F, Ugolini G, Sidorenkov G, Montroni I, Vigano $\mathrm{A}$, et al. Long-term survival and risk of institutionalization in onco-geriatric surgical patients: long-term results of the PREOP study. J Am Geriatr Soc. 2020;68:1235-41. https://doi. org/10.1111/jgs.16384

37. Bolger JC, Loughney L, Tully R, Cunningham M, Keogh S, McCaffrey $\mathrm{N}$, et al. Perioperative prehabilitation and rehabilitation in esophagogastric malignancies: a systematic review. Dis Esophagus. 2019;32:doz058. https://doi.org/10.1093/dote/doz058

38. Rønning B, Wyller TB, Nesbakken A, Skovlund E, Jordhøy MS, Bakka A, et al. Quality of life in older and frail patients after surgery for colorectal cancer-a follow-up study. J Geriatr Oncol. 2016;7:195-200.
39. Traa MJ, Orsini RG, Oudsten BLD, De VJ, Roukema JA, Bosman SJ, et al. Measuring the health-related quality of life and sexual functioning of patients with rectal cancer: does type of treatment matter? Int J Cancer. 2014;134:979-87.

\section{SUPPORTING INFORMATION}

Additional supporting information may be found online in the Supporting Information section.

How to cite this article: Ketelaers SH, Voogt EL, Simkens GA, et al. Age-related differences in morbidity and mortality after surgery for primary clinical T4 and locally recurrent rectal cancer. Colorectal Dis. 2021;23:1141-1152. https://doi. org/10.1111/codi.15542 